\title{
Antibiotic feed additives and livestock production
}

By D. S. PARker and D. G. Armstrong, Department of Agricultural Biochemistry and Nutrition, Faculty of Agriculture, University of Newcastle upon Tyne, Newcastle upon Tyne NE1 7RU

Hespell (1987) has dealt with the application of some of the newer techniques of biotechnology in modifying the rumen microbial biomass with the objective of enhancing efficiency of feed utilization by the host animal. The advantage to be so gained from modifying the rumen microbial population has already been realized in the widespread use of antibiotics such as avoparcin and monensin as feed additives in beef and sheep meat production (Armstrong \& Gilbert, 1985). Since virtually all the gut-active growth promoters for cattle, sheep, pigs and poultry in use today are antimicrobials, predominantly antibiotics, it is reasonable to conclude that their effectiveness lies in their impact on the microbiota of the alimentary tract.

While the abundance of the microbial population in the fore stomachs and caecum of ruminants is universally realized, it is not so well recognized that large numbers of bacteria are also present in the stomach and small intestine of the pig and in the crop and small intestine of the bird (Hedde, 1984; Lee, 1985). The microbial population of the gastrointestinal tract in most warm-blooded animals comprises two distinct populations the first occurs free or attached to digesta within the lumen of the tract and the second exists in intimate association with the epithelium of the tract (for references, see Armstrong, 1986). The manipulation of the numbers and species of micro-organisms in the various regions of the tract will influence the nature and availability of metabolites eventually available to the host animal; it is the consequences of this selective modification of the bacterial flora within the gut on nutrient availability and absorption by the host animal that is the subject of the present paper. No mention will be made here of the efficacy of antibiotic growth promoters (for appropriate references, see Armstrong, 1984, 1986), nor will comment be made on the modes of action of the different antibiotics (antimicrobials) in controlling primarily gram positive as distinct from gram negative micro-organisms (for further information on this aspect, see Franklin \& Snow, 1981; Brander, 1986).

\section{Events in the rumen}

Improved measurements of feed conversion efficiency and growth rate in steers fed on both concentrate- or forage-based diets together with antibiotic feed additives are associated with changes in the molar proportions of volatile fatty acids (VFA) in the rumen, increasing that of propionate at the expense of acetate and butyrate. In studies with monensin in which VFA production rates in the rumen have been measured (Van Maanen et al. 1978; Rogers \& Davis, 1982) it is apparent that monensin inclusion results in increased VFA production per kg dry matter intake in addition to shifts in VFA molar proportions in rumen fluid. The rates of production of individual VFA following monensin inclusion showed increases in propionate and, to a lesser extent, acetate production with a decrease in that of butyrate. In addition to altering VFA metabolism, methane production was reduced in steers (Thornton \& Owens, 1981) and sheep (Allen, 1981), confirming major shifts in the activity of the rumen microbial population. Studies on the growth of individual bacterial species (Chen \& Wolin, 1979) have shown that Ruminococcus albus, Ruminococcus flavefaciens and Butyrivibrio fibrisolvens were all 
highly sensitive to the effect of the ionophore antibiotics monensin and lasalocid whereas Bacteroides succinogenes and Bacteroides ruminicola, both important succinate producers, were not. Selenomonas ruminantium is also resistant to these antimicrobial agents and plays a major role in the rumen with respect to propionate production. Chen \& Wolin (1979) suggested that the reduction in methane production associated with monensin treatment may be an indirect one via inhibition of precursor production (formate and hydrogen). Similar results have also been obtained with avoparcin for laboratory cultures of $R$. flavefaciens and $B$. fibrisolvens which were shown to be susceptible to the antibiotic (Stewart et al. 1983). A more recent study (Stewart \& Duncan, 1985) in which the effect of inclusion of avoparcin in the diet of sheep on rumen cellulolytic bacteria was assessed showed that avoparcin reduced the number of ruminococci present although the total number of bacteria remained constant. Avoparcin appeared to shift the balance of the cellulolytic bacterial population from ruminococci to $B$. succinogenes, a species able to solubilize particularly inaccessible cellulose such as that in straw cell-walls associated with lignin.

A number of studies have indicated that monensin treatment results in an increase in the flow of dietary protein to the duodenum and a decrease in the efficiency of microbial protein synthesis within the rumen (Isicheri \& Bergen, 1980) due to the increased maintenance requirements of the micro-organisms at low growth rates (Stouthamer \& Bettenhaussen, 1973). A further indicator of altered nitrogen metabolism during ionophore treatment is the reduction in rumen ammonia levels in both steers (Dinius et al. 1976; Hanson \& Klopfenstein, 1979) and sheep (Ricke et al. 1984) although this response has not been apparent in all studies (Wahle \& Livesey, 1985). Recent findings from steers in which monerisin or lasalocid were included in the diet showed that both these compounds have an effect on urease (EC 3.5.1.5) activity in rumen fluid, reducing it by 66 and $28 \%$ respectively (Starnes et al. 1984). Bacterial urease is a nickel-dependent enzyme and monensin has been shown to inhibit transport of this element in Methanobacterium bryantii (Jarrell \& Sprott, 1982) affording a possible explanation for the decrease in both ammonia and methane concentrations in rumen fluid of treated animals.

The relation between changes in rumen fermentation variables in animals given feed-additive antibiotics and the increased efficiency of feed utilization has been extensively reviewed (Armstrong, 1984, 1986). The evidence, at least that relating to monensin, shows that a major contribution to enhanced efficiency of feed utilization by ruminants fed on this ionophore antibiotic lies in the increased metabolizable energy content per unit feed dry matter. This results from a reduction in methane-gas production linked to an increase in the proportion and amount of propionic acid yielded in the fermentation and, to a lesser extent, reduced $\mathrm{N}$ excretion via the urine, the last-mentioned reflecting a protein-sparing effect. Notwithstanding the foregoing it is clear that much remains to be learnt concerning rumen fermentation in the presence of sub-therapeutic levels of antibiotics before a full understanding of the benefits realized is possible.

\section{Events in the small intestine}

As already mentioned, very significant numbers of bacteria are present in the crop of the bird, stomach of the pig and small intestine of both ruminant and non-ruminant species. Present understanding of the relation between the bacterial population within the small intestine and functional activity of the tissues of the small intestine is largely based on studies with germ-free and gnotobiotic animals, particularly the chick (Siddons \& Coates, 1972; Coates, 1980; Yokota \& Coates, 1982). These studies indicate that in germ-free animals there are specific changes in the histology of the villi of the small 
intestine with a reduction in the rate of enterocyte-cell migration up the villus. In addition there are changes in enzyme activity and rates of nutrient absorption from isolated loops of the small intestine (for review, see Armstrong, 1986). The extent to which comparable changes are seen in animals given sub-therapeutic levels of antimicrobials in their diets over considerable periods of time is less well established. In the following each of the factors will be considered separately.

Changes in the gut wall. It has been known for many years that the inclusion of antibiotics in the diets of pigs results in a reduction in the weight of the small intestine (Taylor \& Harrington, 1955; Braude et al. 1955). Recent experiments at Newcastle show that inclusion of an antibiotic in the diet of pigs results in significant changes in small intestinal morphology with elongated villi and a higher villus:crypt ratio in treated animals which is indicative of a lower rate of enterocyte-cell migration when compared with controls (P. J. Johnston, D. S. Parker and D. G. Armstrong, unpublished results). The realization that a number of local and systemic factors, including changes in diet, influence the rate of cell proliferation in the villus crypts (for review, see Smith, 1985) suggests that a reduction in the production of toxic by-products normally arising from microbial activity in digesta could reduce enterocyte damage and therefore lower cell renewal rates. Degradation of endogenous urea to ammonia has been proposed as one of the negative influences of the microbial flora in the small and large intestine (Visek, 1978) although there is no clear evidence as to the level of ammonia in the gastrointestinal tract which might be considered harmful to the enterocyte cell. Several authors have identified decarboxylation and deamination of amino acids as a result of microbial metabolism as possibly influencing both amino acid supply to the host animal and also producing toxic or pharmacologically active amines which might affect enterocyte function. Studies with pigs (Dierick et al. 1986a,b), in incubation experiments with digesta and also in in vivo experiments with surgically modified animals, indicate that a number of antimicrobial compounds, e.g. virginiamycin, spiramycin, carbadox and copper sulphate, significantly reduce the levels of ammonia and the production of a number of amines, particularly cadaverine.

Interference in bile acid metabolism. Metabolism of bile acids within the small intestine of the chick by the microbial flora has been postulated as resulting in impaired lipid absorption although the significance of this process in growth depression in the bird is uncertain (Fuller, 1984). Recent experiments with pigs have shown that bile acid metabolism is affected by the inclusion of carbadox in the diet (Tracy et al. 1986), resulting in a decrease in the biological half-life of chenodeoxycholic acid in blood and a significant increase in faecal excretion of the bile acid. These results are somewhat confounded by an apparent increase in chenodeoxycholic acid concentration in the portal blood of the treated animals, although this may reflect increased enterohepatic recycling of the bile acid as a result of decreased microbial degradation to the toxic lithocholic acid in the intestine.

Enzyme changes. The induction of sucrase (EC 3.2.1.48) activity in crypt cells of rats fed on sucrose (Raul et al. 1980) and the differences reported in a wide range of brush-border enzyme activities between conventional and gnotobiotic animals (Bruckner \& Szabo, 1984) are further examples of adaptation of the enterocyte cells to a changing environment. In addition the inclusion of avoparcin in the diets of rats resulted in an increase in aminopeptidase (EC 3.4.11.11) activity in the ileal mucosa (Parker et al. 1984) while raised sucrase activity has been observed throughout the length of the small intestine of pigs fed on diets containing another antimicrobial feed additive $(P . J$. Johnston, D. S. Parker and D. G. Armstrong, unpublished results). The turnover of brush-border proteins including disaccharidases is markedly affected by pancreatic 
protease activity and in cases of pancreatic occlusion increased expression of enzyme activity in the brush border has been observed (Alpers \& Tedesco, 1975). It has been suggested that bacterial protease activity may also play a role in the turnover of brush-border proteins (Alpers, 1983) in which case modification of bacterial numbers, particularly of Bacteroides species, might be anticipated to increase mucosal enzyme activity.

Efficiency of absorption. The relation between the expression of enzyme activity and functional activity of the small intestine as measured by nutrient uptake is not clear. It has been argued in the past that the gastrointestinal tract has sufficient capacity for efficient absorption overall and that an increase would be of no obvious benefit to the animal. The limited information available, however, does suggest that in sheep avoparcin improves the net absorption of amino acids from the small intestine (Macgregor \& Armstrong, 1984) and in pigs, experiments with virginiamycin resulted in an enhanced uptake $(9 \%)$ of free amino acids from a temporarily isolated intestinal loop (Dierick et al. 1986a).

The ionophore antibiotics and small intestine. The ionophore antibiotics such as monensin are very effective coccidiostats for poultry and thus in poultry feeds contribute to the maintenance of health in the face of environmental stress and the challenges that arise as a result of intensive livestock production practices. Ionophores are not, however, growth promoters in poultry, in contrast to the situation with ruminants (Armstrong, 1986). Ionophore antibiotics are not of course used clinically since, unlike most other antibiotics, they are equally toxic to eukaryotic and prokaryotic cells (Hammond \& Lambert, 1978).

It is known that in cattle more than $70 \%$ of monensin is excreted intact in the faeces (Armstrong, 1984) and thus it is reasonable to conclude that significant amounts of ionophore antibiotics pass through the small intestine of the ruminant daily. The same will of course be true for poultry when these are receiving ionophore antibiotics as coccidiostats. Thus it is relevant to question the effect that the presence of such ionophore antibiotics have in the small intestine in addition to their anticoccidial action.

The influence of the ionophore antibiotics in the small intestine might be anticipated to involve direct effects on enterocyte membrane function. Monensin has been shown to affect $\mathrm{Na}^{+}, \mathrm{K}^{+}$-ATPases and $\mathrm{Na}^{+}$transport across membranes. It has been suggested that these effects would influence the carrier systems within the brush border enhancing, for example, amino acid absorption linked to electrochemical gradients but depressing uptake linked to $\mathrm{Na}^{+}$symports (Bergen \& Bates, 1984). Both monensin and lasalocid bind a wide range of monovalent ions and in addition lasalocid binds several divalent ions including calcium, magnesium and cupric ions. It is possible, therefore, that these compounds could influence the availability of both macro- and micro-elements present in feedstuffs. Studies in the chicken have shown that both monensin and lasalocid reduce the incorporation of ${ }^{45} \mathrm{Ca}$ into duodenal mucosal samples although when these studies were repeated with ${ }^{64} \mathrm{Cu}$, monensin reduced and lasalocid increased incorporation into the tissue (Elsasser, 1984). These studies did not distinguish between reduced uptake via the mucosal surface or increased transfer across the serosal membrane but do indicate that the presence of ionophores in the diet influences the transport across the epithelium of the gastrointestinal tract. Elsasser (1984) also reports that in routine screening of sheep fed on similar diets with and without monensin or lasalocid, serum $\mathrm{Ca}$ was significantly lower and phosphorus higher when monensin was included in the diet but not when lasalocid was present. 


\section{Metabolic effects of antibiotic feed additives}

In ruminant animals the increase in propionate availability in the rumen following antibiotic administration has been shown to raise blood glucose concentration (Potter et al. 1976; Raun et al. 1976) and also glucose entry rate in 104-d pregnant ewes (Oddy $e t$ al. 1978) and in cattle (Van Maanen et al. 1978). A recent study by Wahle \& Livesey (1985), in which both barley-based and forage-based diets were given to sheep with and without monensin supplementation, showed that propionate oxidation by liver slices increased following monensin treatment and, in the case of the concentrate diet, significant amounts of propionate escaped liver metabolism and were detectable in peripheral blood. Despite the observed increase in propionate availability there was, however, no change in plasma glucose concentrations; plasma insulin levels were reduced when compared with control values, a finding that warrants further study. The influence of monensin on overall body metabolism has also been investigated in pregnant ewes (Austin \& Wilde, 1985) where inclusion of the ionophore in the diet had positive effects on blood glucose levels, reduced blood 3-hydroxybutyrate concentrations in late pregnancy and eliminated clinical signs of pregnancy toxaemia. This was achieved despite a decrease in feed intake by the treated animals suggesting an overall improvement in efficiency of feed utilization rather than increased tissue mobilization.

Experiments designed to investigate the influence of treatment of young growing pigs with carbadox on fasting metabolic rate and thyroid function (Yen et al. 1985) were unable to detect any differences between control and treatment groups. Pigs fed on diets containing carbadox showed improved weight gain and feed conversion efficiency when compared with controls and, as expected, the weight of the small intestine was significantly reduced. In view of the high metabolic activity associated with gut tissues (Webster, 1981) it would seem reasonable to conclude that, at least with simplestomached animals in which low-level antibiotic administration is known to reduce epithelial tissue mass and rate of epithelia cell turnover, part at least, of the improved animal performance may well be due to reduced energy costs of gut metabolism.

\section{Concluding remarks}

Undoubtedly the presence of antibiotics in the digesta of the stomach and small intestine does have significant effects on the epithelial tissue with the possible implication of a lowered energetic cost to the body for the maintenance of this very active tissue and also improvement in nutrient absorption. Certainly there are changes in the enzymology of the intestinal wall and evidence that points to a reduction in the microbial production of toxic metabolites such as ammonia and amines within it. In the ruminant animal it is clear that there are significant additional changes in nutrient availability arising from events in the rumen which contribute to improved feed conversion efficiency in growing animals. The presence of antibiotics in the digesta of the caecum and hind-gut are likely to exert additional effects but, as yet, little is known about the significance of the contribution of such effects to overall improvements in efficiency of livestock production.

\section{REFERENCES}

Allen, J. D. (1981). Studies on manipulation of rumen fermentation. PhD Thesis, University of Newcastle upon Tyne.

Alpers, D. H. (1983). In Protein Metabolism and Nutrition, pp. 319-331 [R. Pion, M. Arnal and P. Bonin, editors]. European Association for Animal Production Publication no. 61. Paris: INRA.

Alpers, D. H. \& Tedesco, F. J. (1975). Biochimica et Biophysica Acta 401, 28-40. 
Armstrong, D. G. (1984). In Antimicrobials and Agriculture, pp. 331-347 [M. Woodbine, editor]. London: Butterworths.

Armstrong, D. G. (1986). In Control and Manipulation of Animal Growth, Proceedings of the University of Nottingham 43rd Easter School, 15-18 April 1985, pp. 21-37 [P. J. Buttery, D. Lindsay and N. B. Haynes, editors]. London: Butterworths.

Armstrong, D. G. \& Gilbert, H. J. (1985). Journal of the Science of Food and Agriculture 36, 1039-1046.

Austin, A. R. \& Wilde, R. M. (1985). British Veterinary Journal 141, 628-634.

Bergen, W. G. \& Bates, D. B. (1984). Journal of Animal Science 58, 1465-1483.

Brander, G. C. (1986). Chemicals for Animal Health Control. London: Taylor and Francis.

Braude, R., Coates, M. E., Davies, M. K., Harrison, G. F. \& Mitchell, K. G. (1955). British Journal of Nutrition 9, 363-368.

Bruckner, G. \& Szabo, J. (1984). In Advances in Nutritional Research vol. 6, pp. 271-332 [H. H. Draper, editor]. New York: Plenum Press.

Chen, M. \& Wolin, M. J. (1979). Applied Environmental Microbiology 38, 72-77.

Coates, M. E. (1980). In Growth in Animals, pp. 175-188 [T. L. J. Lawrence, editor]. London: Butterworths.

Dierick, N. A., Vervaeke, I. J., Decuypere, J. A. \& Henderickx, H. K. (1986a). Livestock Production Science 14, 161-176.

Dierick, N. A., Vervaeke, I. J., Decuypere, J. A. \& Henderickx, H. K. (1986b). Livestock Production Science 14, 177-193.

Dinius, D. A., Simpson, M. E. \& Marsh, P. B. (1976). Journal of Animal Science 42, 229-234.

Elsasser, T. J. (1984). Journal of Animal Science 59, 845-853.

Franklin, T. J. \& Snow, G. A. (1981), Biochemistry of Microbial Action, 3rd ed. London: Chapman and Hall.

Fuller, R. (1984). Proceedings of the Nutrition Society 43, 55-61.

Hammond, S. M. \& Lambert, P. A. (1978). Antibiotics and Antimicrobial Action. London: Edward Anold.

Hanson, T. L. \& Klopfenstein, T. F. (1979). Journal of Animal Science 48, 474-479.

Hedde, R. D. (1984). In Antimicrobials and Agriculture, pp. 359-368 [M. Woodbine, editor]. London: Butterworths.

Hespell, R. B. (1987). Proceedings of the Nutrition Society 46, 407-413.

Isicheri, C. O. \& Bergen, W. G. (1980). Journal of Animal Science 51, Suppl., 371-372.

Jarrell, K. F. \& Sprott, G. D. (1982). Journal of Bacteriology 151, 1195-1203.

Lee, A. (1985). Advances in Microbial Ecology 8, 115-162.

Macgregor, R. C. \& Armstrong, D. A. (1984). Canadian Journal of Animal Science 64, Suppl., 134-135.

Oddy, V. H., Cook, J. B., Jones, A. W. \& Wells, B. A. (1978). Proceedings of the Australian Society of Animal Production 12, 144.

Parker, D. S., Macgregor, R. C., Finlayson, H. J., Stockill, P. \& Balios, J. (1984). Canadian Journal of Animal Science 64, 136-137.

Potter, E. L., Cooley, C. O., Richardson, L. F., Raun, A. P. \& Rathmacher, R. P. (1976). Journal of Animal Science 43, 665-669.

Raul, F., Simon, P. M., Kedinger, M., Grenier, J. F. \& Haffen, K. (1980). Biochimica et Biophysica Acta 630, $1-9$.

Raun, A. P., Cooley, C. O., Potter, E. L., Rathmacher, R. P. \& Richardson, L. F. (1976). Journal of Animal Science 43, 670-677.

Ricke, S. C., Berger, L. L., Van der Aar, P. J. \& Fahey, G. C. (1984). Journal of Animal Science 58, 194-202.

Rogers, J. A. \& Davis, C. L. (1982). Journal of Dairy Science 65, 944-952.

Siddons, R. C. \& Coates, M. E. (1972). British Journal of Nutrition 27, 101-112.

Smith, M. W. (1985). Annual Reviews of Physiology 47, 247-260.

Starnes, S. R., Spears, J. W., Froetschel, M. A. \& Croom, W. J. (1984). Journal of Nutrition 114, 518-525.

Stewart, C. S., Crossley, M. V. \& Garrow, S. H. (1983). European Journal of Applied Microbiology and Biotechnology 17, 292-297.

Stewart, C. S. \& Duncan, S. H. (1985). Journal of General Microbiology 131, 427-435.

Stouthamer, A. H. \& Bettenhaussen, C. (1973). Biochimica et Biophysica Acta 301, 53-70.

Taylor, J. H. \& Harrington, G. (1955). Nature 175, 643-644.

Thornton, J. H. \& Owens, F. N. (1981). Journal of Animal Science 52, 628-634.

Tracy, J. D., Allhands, R. V., Savage, D. C. \& Jensen, A. H. (1986). Journal of Animal Science 62, 997-1004.

Van Maanen, R. W., Herbein, J. H., McGilliard, A. D. \& Young, J. W. (1978). Journal of Nutrition 108, 1002-1007.

Visek, W. J. (1978). Journal of Animal Science 46, 1447-1469.

Wahle, K. W. J. \& Livesey, C. T. (1985). Journal of the Science of Food and Agriculture 36, 1227-1236. 
Webster, A. J. F. (1981). Proceedings of the Nutrition Society 40, 121-128.

Yen, J. T., Nienaber, J. A., Pond, W. G. \& Varel, V. H. (1985). Journal of Nutrition 115, 970-979.

Yokota, H. \& Coates, M. E. (1982). British Journal of Nutrition 47, 349-356. 